\title{
DA PRODUÇÃO À PUBLICIDADE: UMA QUESTÃO DE CONSUMO
}

KARLA PATRIOTA BRONSZTEIN

IARA MARGOLIS 


\section{DA PRODUÇÃO À PUBLICIDADE: UMA QUESTÃO DE CONSUMO}

Resumo: A crescente e constante adesão dos indivíduos à lógica do capital vem assumindo uma extensão global. Assim, pretendemos refletir sobre produção, consumo e publicidade, considerando aspectos significativos como a criação de identidades, a administração da produção e o planejamento da obsolescência. A partir de tais pilares demonstraremos a convergência entre os temas e os impactos verificados na sociedade moderna.

Palavras-chave: Produção em massa; Planejamento da obsolescência; Identidade moderna; Consumo; Publicidade.

\section{DE LA PRODUCCIÓN A LA PUBLICIDAD: UNA CUESTIÓN DE CONSUMO}

Resumen: La creciente e constante adhesión de los individuos a la lógica del capital ha asumido una extensión global. Así, pretendemos reflexionar sobre producción, consumo y publicidad, considerando aspectos significativos como a creación de identidades, la administración de la producción y el planeamiento de lo obsoleto. A partir de tales pilares, promoveremos la convergencia entre los temas y los impactos verificados en la sociedad moderna.

Palabras clave: Producción en massa; Planeamiento de lo obsoleto; Identidad moderna; Consumo; Publicidad.

FROM PRODUCTION TO ADVERTISING: CONSUMPTION ISSUE

Abstract: The increasing and constant adoption by individuals of the logic of capital has been assumed a global extension. Therefore, we intend to consider production, consumption and advertising, taking into account significant aspects such as the creation of identities, the administration of production and the planning of obsolescence. Starting from these bases, we will analyze the existing relations between the themes and their impact in modern society.

Keywords: Mass production. Planning of obsolescence. Modern identity. Consumption. Advertising. 


\section{INTRODUÇÃO}

Os seres vivos nasceram para produzir, consumir e transformar o seu habitat. Conforme Engels (apud CASAQUI, 2008, p.203) enfatiza em sua tese, a diferença brutal entre o ser humano e os outros animais consiste na capacidade do primeiro em modificar a natureza em função dos seus objetivos, para dominá-la, servir-se dela e viver explorando seus recursos. Assim, para satisfazer e atender as necessidades e os desejos humanos surgiu a produção.

Com o passar do tempo, o homem foi se aperfeiçoando, até chegar à produção em larga escala. A nova dimensão produtiva transmutou, por conseguinte, as noções anteriores do próprio sistema de produção, a sociedade, a comunicação estabelecida entre as empresas e os consumidores, o consumo e a forma de relacionamento homem-mundo. Tais aspectos geraram uma ligação de dependência entre dois campos: o da produção e o da publicidade. Essas duas áreas, aparentemente distintas, mantêm uma interface significativa sendo geradora de impactos consideráveis na sociedade moderna. Com efeito, imersos em uma sociedade cujos padrões de consumo são massificados e as ofertas de bens padronizadas, nos vemos diante de inúmeras pressões exercidas sobre o consumidor, entre elas a publicidade, com seus modelos de comportamento a seguir.

Não obstante o desejo de consumir incluir os mais característicos propósitos, os quais tendem a variar conforme diversos fatores - sejam eles sociais, culturais ou simplesmente características grupais - a oferta, normalmente, excede a procura. Tal circunstância implica em muitos recursos estratégicos de marketing para escoar a produção. Soma-se a isso o alargamento na oferta de bens normalizados, produzidos a baixos custos e resultantes da produção em série, que mesmo atrativos em primeira instância, têm uma duração efêmera, já que as necessidades de produzir e escoar são, invariavelmente, permanentes.

Em um cenário assim concebido, a crescente adesão dos indivíduos à lógica do capital não só se tornou constante, como assumiu, nos últimos anos, uma extensão global. Por conta de tal conjuntura, neste trabalho, pretendemos refletir sobre produção, consumo e publicidade, considerando aspectos significativos como a criação de identidades, a administração da produção e o planejamento da obsolescência. A partir de tais pilares, promoveremos uma análise das relações existentes entre os temas e os impactos verificados na sociedade moderna, cenário da convergência entre produção e comunicação publicitária. 


\section{A IDENTIDADE VIA CONSUMO}

É senso comum o aceite de que estamos mergulhados, na contemporaneidade, em uma "Sociedade de Consumo". Autores como Baudrillard (1995), Bauman (2008), Featherstone (1995) e Liposvesty (2007) estruturam suas análises a partir da concepção desta como uma sociedade na qual o exercício do consumo molda todas as relações dos indivíduos - o que tem pautado grandes reflexões para o entendimento social, cultural e econômico da conjuntura em que estamos inseridos.

É fato que o consumo tem sua origem nas necessidades fisiológicas, contudo, ao longo do tempo, atuou de forma patente até na criação da identidade do ser humano moderno. Hoje, os bens que possuímos e as vestimentas que usamos nos definem como indivíduos e seres sociais. Como bem pontua Bourdieu (1984), o gosto, que determina nossas inclinações e atos de consumo, tem uma origem social e está relacionado ao habitus - conceito desenvolvido pelo autor para evidenciar que as escolhas, os hábitos e as práticas, além das ações em situações diárias, são normalmente relacionadas a uma dada classe social e à posição do individuo na sociedade.

O consumo é, portanto, o sistema que classifica bens e identidades; coisas e pessoas "[...] por isso, podemos dizer que os produtos e serviços falam entre si, falam conosco e falam sobre nós" (ROCHA; BARROS, 2008, p. 192). Temos, em outra vertente, a concepção da identidade como relacional, simbólica e social - marcada, por conseguinte, pela diferença de símbolos concretos que ajudam na identificação das relações sociais (WOODWARD, 2012).

Desde Ford, que iniciou a produção em massa padronizada e a linha de montagem, o mundo se tornou um lugar mais "comercial", no qual: o que "eu" compro, "eu" obtenho; consequentemente o que "eu" obtenho, "eu" sou. Como em uma questão de lógica: o que eu posso comprar, eu posso ser. Com efeito, não é difícil compreender, portanto, a afirmação de que "o trabalhador produz o capital, o capital produz o trabalhador. Desse modo, ele se produz a si mesmo, e o homem como trabalhador, como mercadoria, constitui o produto de todo o processo" (MARX apud CARRASCOZA et al, 2007, p.68).

Contudo, mesmo que padrões sejam reproduzidos, há ainda um longo caminho separando a produção do consumo (FREDERICO, 2008, p.87). O fato é que, com o advento da produção em massa para um mercado que principiava 
a superação da fase do consumir apenas o essencial, viram-se os industriais forçados a encontrar meios rápidos de escoar o excesso da produção de máquinas cada vez mais aperfeiçoadas e velozes. E o meio mais eficaz encontrado foi a publicidade (SANT'ANNA apud ANDRADE, 2007, p.35). Dessa forma, a produção cria produtos seriados, impessoais e anônimos que serão consumidos por pessoas individualizadas e com singularidades. O papel da publicidade, por conseguinte, é ligar esses atributos aos seres humanos e aos seus domínios do consumo (CARRASCOZA et al, 2007, p. 73).

Numa ampliação da visão, podemos nos ancorar na emergência de uma sociedade líquida (BAUMAN, 2008), na qual o homem moderno vive e experimenta suas relações de consumo. Nesta, nada é constante e tudo é variável - na qual o "ter" é determinante do "ser". Na sociedade de essência líquida, apresentada a partir das postulações de Bauman, a percepção social do outro transcende o caráter ético, moral, de valores ou conteúdo espiritual. A humanidade, contraditoriamente, ao se liquidificar, se materializou: para o ser humano moderno ser, necessariamente precisa possuir e demonstrar que possui.

Soma-se a isso o fato de que, na contemporaneidade, surge uma nova dimensão de consumo. O que, na visão de Baudrillard (1995), é transmutado para um consumo que não é mais de objetos que atendam necessidades reais do ser humano, mas torna-se linguagem, uma ordem de significação. Logo, nessa nova realidade, o consumo dos objetos deixa de ocorrer em função da sua utilidade e passa a ter a valor como sistema de signos.

Significados estes, como bem delineia Carreira (2007, p. 103), que se subdividem no resultado funcional, da utilização prática, no emocional e na parte estética, e que juntos refletem os atributos da identidade. Para o consumidor, tal processo de troca entra em um sistema de valorização que oscila entre a razão e a emoção, entre o custo e o benefício e o status.

É justamente por conta dessa típica conjuntura que Rocha e Barros (2008, p.182) ressaltam que o conhecimento dos aspectos culturais atuantes no consumo de grupos sociais específicos é uma forma singular de mapeamento da cultura moderno-contemporânea. Tão somente porque, como defendem os autores, o "consumo não pode ser explicado, na extensão de seu impacto social, através de visões moralizadoras, mercadológicas ou reducionistas". Sua abrangência acrescenta complexidade a distintas dimensões da experiência 
contemporânea. E concluem: "a cultura, tal como podemos reconhecê-la no cotidiano, passa pelo fenômeno do consumo" (idem).

Obviamente, pensar em cultura e identidade via consumo, nos faz considerar visões como a de Bauman (2008, p.20), ao afirmar, por exemplo, de que na sociedade de consumidores ninguém pode se tornar sujeito sem primeiro virar mercadoria, e ninguém pode manter segura sua subjetividade sem reanimar, ressuscitar e recarregar, de maneira perpétua, as capacidades esperadas e exigidas de uma mercadoria vendável.

É válido ressaltar ainda que, mesmo quando o consumo é alicerçado pela realização do desejo pessoal, pelo menos "em tese”, imprime-se um sentido de liberdade individual, e tem-se como contrapartida básica a dependência em relação ao consumo dito social, ou simplesmente a exigência de ser consumidor para poder ser cidadão (CASAQUI, 2008, p.207).

Dessa forma, o consumo se constitui como uma ampliação da identidade de cada cidadão do mundo capitalista moderno. Como consequência, consumir torna-se um dever social: todos devem ser compradores ativos e efetivos dos bens e serviços que o mercado oferece - o que transforma os pobres de hoje em meros "não consumidores" (BAUMAN, 2008, p.160).

Mais ainda, como ressalta Casaqui (2008, p.208), aqueles que não se enquadram na sociedade de consumo, no plano simbólico, são reprimidos e banidos dos benefícios ofertados pelas mercadorias. Assim, "o desejo de pertencimento na sociedade de consumo fala mais alto - aqui, 'vergonha' é não consumir." (ROCHA; BARROS, 2008, p.196). O que resulta em um ser humano que é, ao mesmo tempo, o promotor da mercadoria e a mercadoria que promove. Logo somos, simultaneamente, os produtos e seus agentes de marketing. (BAUMAN, 2008, p.13).

Casaqui (2008, p.213) ainda afirma que as mercadorias, revestidas por atributos intangíveis, representam a dinâmica que faz do consumo simbólico e da aquisição de produtos um ato de caráter identitário, social, cultural e político. Nesse sentido, Kreutz e Fernández (2009, p.93) complementam sua análise pela ótica dos diversos comportamentos das marcas que atualmente disputam o mercado, imprimindo em si traços de identidade que permitem ao consumidor a identificação de seus valores no objeto observado/desejado.

Já Haug (apud CASAQUI, 2008, p.206) sintetiza a identidade-consumo afir- 
mando que a aparência oferece-se como se anunciasse a satisfação: ela descobre alguém, lê os desejos em seus olhos e mostra-os na superfície da mercadoria. De tal modo que, nessa sociedade liquida, "os sujeitos se configuram e se re-configuram sem cessar" (ENNE, 2006 p.20). Se tornando o que são, porque os outros o reconhecem como tal (MAFFESOLI apud BAUMAN, 2008, p.107).

Todo esse mosaico identitário nada mais é do que uma espécie de autoafirmação pessoal perante a sociedade e o habitus no qual o consumidor se insere, que vem aclarar porque fazemos algumas coisas e não outras e porque fazemos de um modo e não de outro. "Nossas decisões de consumo são simples reflexos de nossa posição social” (FILHO; LOPES, 2008, p.114) nos conferindo, por conseguinte, personificações identitárias referentes ao que consumimos. Na mesma direção temos a constatação de que as "identidades adquirem sentido por meio da linguagem e dos sistemas simbólicos pelas quais elas são representadas" (WOODWARD, 2012). A autora ainda assinala que a identidade, que é relacional, é marcada pela diferença, esta última, também sustentada pela exclusão, possibilitando associar a identidade da pessoa e as coisas que ela usa.

O ponto a ser questionado, no entanto, é: quais são as consequências para tal ausência de solidez? Indivíduos que se moldam, julgam e que têm o consumo de produtos e serviços como importantes para a sua própria definição, geram uma sociedade pautada nesses valores. O que mobilizará e impactará diretamente toda a sua cadeia de suprimentos e reabastecimento; nas necessidades e nos desejos; e no impacto de futuros: tanto ambiental quanto sócio-cultural.

Enfim, o ser humano consome em busca da sua aceitação social, tentando, ao mesmo tempo, se diferenciar da massa e se igualar aos seus grupos de referência ${ }^{1}$ - o que o faz alicerçar sua própria identidade no consumo, moldando-a de acordo com suas "necessidades", sejam estas de ordem material, social ou simbólica. É justamente nesse espaço que a produção em massa e a publicidade encontram terreno fértil e oportuno para o alargamento de suas atuações no seio da sociedade.

1 Grupos de pessoas que influenciam os pensamentos, os sentimentos e os comportamentos do consumidor. 


\section{A PRODUÇÃO E O CONSUMO}

Não é novidade que produção e consumo estão relacionados e são inerentes à vida, como, por exemplo, o consumo de oxigênio ou de alimentos e suas relações com a produção de gás carbônico e lixo - o que transforma e condiciona o meio a nunca mais voltar a ser o mesmo. Com efeito, é a produção que permite, via seu consumo, a nossa existência.

Foi com o passar do tempo que as formas de produção e consumo, com todos os seus desdobramentos e consequências foram se transformando, até chegar à sociedade atual. Segundo Davis et. al. (2003, p.33), até o final do século XVIII, a agricultura era a indústria predominante da época e as mercadorias eram produzidas artesanalmente. Paulatinamente grandes avanços, desencadeadores de significativas mudanças, foram marcando época. Em 1765, Watt inventou a máquina a vapor, alicerçando a revolução Industrial. No início do século XIX, Eli Whitney apresentou o conceito de padronização e Frederic Taylor introduziu a administração científica - o que trouxe novas visões para a produção. Em 1913, Ford revolucionou o mundo industrial com a linha de montagem. Todos esses fatores, juntos, resultaram no atual mundo da produção e consumo massificado - que se pode chamar de "a era do excesso".

Muitos fatores, contudo, contribuíram para a formatação dessa era. Um deles, por exemplo, é descrito por Andrade (2007, p.15) ao relatar que o período posterior à segunda guerra mundial se constituiu como o momento singular do afloramento do consumo de bens duráveis e não duráveis - de maneira global e massificada, graças à sistemática das técnicas de consumo e da construção de uma "ideologia consumista".

De forma geral, tal processo de transformação merece uma análise mais detalhada, uma vez que, seus efeitos e implicações passaram a ser, em larga escala, vistos na sociedade moderna repartindo a opinião entre a evolução e a sobrevivência do sistema capitalista. Nesse sentido, é válido pontuar que o modo capitalista de produção não está restrito tão-somente à produção imediata, mas igualmente à circulação de mercadorias, por conseguinte, abrange a permuta de mercadorias por dinheiro e, de modo óbvio, de dinheiro por mercadorias. Tal processo deriva da ocorrência de que o modo de produção capitalista não é, em si, circunscrito ao modo de produção de mercadorias, mas sim 
modo de produção, de mais-valia².

Sendo assim e visando um melhor controle, o homo sapiens desenvolveu a administração da produção para a manutenção do próprio sistema capitalista. Uma forma metodológica, científica e consciente para otimizar e maximizar a produtividade de suas ações. E aqui é importante lembrar que tal conjuntura acentuou as desigualdades do acesso aos meios de produção - o que de igual modo tem influenciado na construção das identidades (relacionadas ao consumo), já que estas, como enfatiza Woodward (2012), também se alicerçam nas "diferenças"3 (que têm causas e consequências materiais), sejam de ordem simbólica e/ou social.

Em paralelo, a noção da necessária "administração da produção" foi referenciada pela própria observação da sua imperativa inserção no contexto social produtivo. Na proposição de Slack et al (2002, p.17), tal administração é imprescindível a partir do fato de ser: a) Importante - devido a sua preocupação com a criação de produtos e serviços da qual todos nós dependemos e, essa criação, é a razão principal para existência de qualquer organização; b) Interessante - destacando o papel desempenhado por ela, no centro de diversas mudanças que, como consequência, afetam o mundo dos negócios e a sua expansão também para o centro das mudanças culturais; e c) Desafiadora - por promover a criatividade - o que viabiliza respostas a tantas mudanças. Dentro dessa perspectiva, portanto, não é difícil concluir que, "Produção é consumo, consumo é produção [...]. Sem a produção não há consumo; sem consumo não há produção" (MARX apud ANDRADE, 2007, p.22).

Logo, a produção vem, por meio da transformação de seus objetos, atender às necessidades e desejos da sociedade, modificando-os e adaptando-os em um processo de retro-alimentação contínuo. Por conseguinte, para dar sustentação a sua produção, encontra o suporte necessário no marketing e na publicidade - o que potencializa a geração de desejos nos consumidores-alvo.

2 O termo mais-valia foi usado por Marx para definir a diferença entre o valor final da mercadoria produzida e a soma do valor dos meios de produção e do valor do trabalho - a maisvalia, portanto foi tida como a base do lucro no Sistema Capitalista. Sweezy \& Baran (1978) defendem o termo "excedente" para definição desse conceito.

3 De acordo com Woodward (2012), a diferença é evidenciada em relação à identidade por meio de sistemas classificatórios que fabricam sistemas simbólicos promotores de exclusão. Assim, tanto as diferenças quanto as identidades são construídas e não dadas e acabadas. 
Tal concepção pode ser mais bem descrita por Carrascoza (2008), quando afirma que, para convencer o público da necessidade de determinados produtos, recorre-se à razão (mostrando a funcionalidade dos mesmos), ou à persuasão, (quando o apelo ocorre no sentido emocional).

Tal investimento encontra respaldo no que aponta Bauman ao postular que a noção de felicidade está no cerne da obsessão dos consumidores que, imersos numa cultura consumista, permanecem fiéis aos seus personagens: "distantes de qualquer satisfação perfeita, consumada, que não requeira novos aperfeiçoamentos" (BAUMAN, 2008, p.146).

O fato é que a própria constituição identitária dos consumidores interfere diretamente nos alicerces da sociedade. Para Andrade (2007, p.22), a mercadoria cumpre um papel valioso para o funcionamento do capitalismo, uma vez que ela é o resultado concreto das necessidades humanas, e é sobre ela que o sistema capitalista pousa suas bases. Mais ainda se a identidade individual do ser implica no ter. Nesse cenário, portanto, quem se destaca na sociedade são os produtos, as empresas e as indústrias, cujo objetivo principal consiste no óbvio: a sobrevivência das organizações que operam no mercado, a partir da geração de lucros cada vez maiores. Portanto, se produz mais para se consumir mais.

Para tal, há a necessidade crescente de produções flexíveis, com portfólios amplos e mutantes, como seus consumidores, gerando o consumo exagerado. Entretanto, as indústrias precisam produzir com a qualidade desejada pelos consumidores, além de estarem de acordo com o que os consumidores desejam naquele momento. É o que Slack (2009, p.44) denomina de confiabilidade: fazer as coisas em tempo para os consumidores receberem seus bens ou serviços exatamente quando necessários ou, ao menos, quando prometidos.

Segundo Casaqui (2008, p.206) o sistema de produção das mercadorias no capitalismo tardio, marcado pela expansão do processo de acumulação e elevação da taxa de lucro, aciona o papel do marketing, que, desde o planejamento dos produtos atribui elementos incorporados ao seu valor de troca, que são derivações e ampliações daquilo que a teoria do marketing denomina "necessidade" e "desejo". Estas são, antes de tudo, expressões sociais do que o homem percebe como essencial para si.

É importante salientar que os processos de produção em massa, ou em larga escala, são os que produzem bens em alto volume e variedade relativa- 
mente estreita, isto é, em termos dos aspectos fundamentais do projeto do produto. (SLACK 2009, p.95). Apesar de, cada vez mais, evoluir a produção em massa flexível, dentro dos parâmetros pré-estabelecidos - o que hoje se convencionou em chamar de "customização". Busca-se, portanto, com a customização, o atendimento de desejos pessoais nascidos no cerne da vida social.

Com efeito, a mudança da produção artesanal para a produção em larga escala afetou o ethos moderno, tornando o cliente mais exigente, cobiçoso à quantidade, mais massificado e menos humanizado. Casaqui (2008, p.211) mostra que o sentido de humanização e de produção artesanal estabelece uma significação publicitária que se sobrepõe, simbolicamente, ao sistema da produção de larga escala, da desumanização das fábricas da empresa, da impessoalidade e do distanciamento da relação entre produtores e consumidores.

Nessa "era do excesso", tudo deve ser planejado e calculado, afinal, qualquer erro resulta em prejuízos, também, em larga escala. Logo, é necessário saber que é prerrogativa empresarial o "dever" de estar preparado para se adaptar a cada instante, já que "o que existe hoje é, necessariamente, o produto de ontem" (LEITE, 2000, p.105).

Entendidas a influência e a dependência entre a criação de identidade, a produção e o consumo, surge o questionamento de como esses fatores se ligam. Rocha (apud CARRASCOZA et al, 2007, p.73) define que, por excelência, o consumo é inerente ao humano, "nele, a palavra fundamental é a troca. Homens, objetos, valores e dádivas são trocados, adquiridos e retribuídos".

Assim sendo, se as percepções acerca dos processos de construção do sujeito foram mudando na modernidade, também as formas de pensar o consumo foram se alterando (ENNE, 2006, p.22). Isso pode ser observado a partir do que postula Kreutz e Fernández (2009, p.91) quando defendem que este início de século foi vivido sob os efeitos de uma nova era tecnológica e de um mundo globalizado. Para os autores, essa conjuntura tem como principais características a mutação, a velocidade, a conectividade e a colaboração - que impulsionam a inovação e o crescimento e atingem todos os setores: cultural, político e econômico. Como consequência, as mudanças alcançam não apenas as organizações, que tentam adequar-se às circunstâncias para sobreviverem, mas também, em grande medida, os atores participantes de todo o processo.

A visão defendida por Maar (2008, p.54) complementa o quadro com a 
grande "novidade" em termos de formação social no século XX: a sociedade de massa - o que resulta em uma espécie de padrão seguido pelos cidadãos das sociedades ocidentais contemporâneas como modelo para encarar todas as suas necessidades (CAMPBELL apud BAUMAN, 2008, p.152)

E o que faz a publicidade? Ela vai encurtar esse caminho, vai acelerar o giro do capital, vai dinamizar o capitalismo, abreviar o tempo de circulação das mercadorias, ligar as empresas aos consumidores acelerando o consumo. Mais ainda: ela tem um papel pedagógico de consumo (BAUMAN, 2008, p. 113), abrangendo "a comunicação midiática que povoa o cotidiano contemporâneo" (CARRASCOZA, 2008, p. 217), com objetivo de incitar o consumo, sendo a mercadoria discriminada no mercado simbólico.

Logo, o estudo do consumidor e suas motivações é um dos aspectos integrais da mercadologia e da publicidade moderna, buscando entender os sonhos, desejos e anseios dos consumidores de modo que os anunciantes possam nestes se basear para projetarem mensagens sobre os produtos (LUKÁCS, 2001, p. 73).

Dentro dessa perspectiva, a publicidade proporciona representações, visões de mundo, anseios, aspirações. Ela traz à tona recortes do cotidiano que lançam nossa experiência humana no universo das marcas, dos produtos e das instituições com fins comerciais, ou seja, essa ligação é dada através do marketing, da mídia e da divulgação publicitária. Andrade (2007, p. 40) ainda pondera que publicidade faz com que o consumidor acredite que a mercadoria é imprescindível para a sua vida e por conta disso vemos, de forma concreta, a introjeção da necessidade de consumo.

Para Castro (2008, p.138) com a consolidação da sociedade de consumo, produtos produzidos em série e em grande escala encontram seu público-alvo graças à sedução da publicidade e da propaganda e dos aprimorados modelos de marketing. Ou ainda, a produção e a ampliação das demandas são verdadeiramente estimuladas pela publicidade - servindo de suporte para o consumo contemporâneo - o que, na visão de Di Nallo (apud CASAQUI, 2008, p.209), se caracteriza por estabelecer pontos de encontro (meeting points) entre produtos, pessoas e formas de comunicação.

Em um entrelaçamento com os objetos da nossa reflexão, os meeting points postulados por Di Nallo (1999), apontam para a fluidez, a descartabilidade e a fuga das identidades quando agregadas ao comportamento de consumo. Nes- 
se sentido, a autora sugere a mudança de foco dos estilos de vida para os estilos de consumo (concebidos dentro da teoria dos meeting points, como "bolhas" ou "esferas" - nas quais transitam os produtos e as marcas ${ }^{4}$ com seus investimentos publicitários para alcance dos potenciais consumidores).

\section{A PRODUÇÃo EM MASSA, O PLANEJAMENTO DA OBSOLESCÊNCIA E A PUBLICIDADE}

Com a produção em massa, não foi preciso muito tempo para perceber que tal mercado emergente era lucrativo e conveniente. Sendo assim, grandes investimentos foram destinados para a criação e aperfeiçoamento da produção em larga escala, surgindo diversas novas marcas e produtos. Contudo, foi necessário algum tempo para perceber que a fabricação de produtos duradouros resultaria em uma estagnação. Alguma atitude seria necessária para a modificação do comportamento do consumidor, algo que o estimulasse a comprar mais por não estar satisfeito com o que já havia adquirido. Assim surgiu, nos Estados Unidos, na década de 1950, a obsolescência planejada:

O planejamento estratégico, aproveitando o consumismo, introduzia no mercado novas versões e a criação da necessidade de aquisição desses novos produtos, seja pelo surgimento de novos status, suprir o desejo dos novos bens, ou ainda, pela vida limitada dos produtos, gerando, desta forma, novos empregos (MARGOLIS, 2012, p.45).

A ideia inicial consistiu na estimulação do consumidor ao mero aumento do consumo. Primeiro a partir da transformação do produto com pequenas, ou grandes, modificações, logo depois com produtos menos duradouros e com invenções, além de outros fatores de base estimulante. Hoje, no entanto, a ideia de obsolescência é bem mais precisa, já que reflete uma realidade que faz parte do nosso cotidiano, observável, por exemplo, na constante descartabilidade (pautada na exploração psicológica da desejabilidade humana) dos objetos que nos cercam.

4 Assumindo propriedades do meeting point para a interação com os consumidores que, imersos nas "bolhas", seriam estimulados no comportamento e na percepção do que delas emana. 
As novas ideias geraram uma nova cultura. Peinado e Graeml (2007, p. 283) destacam a necessidade de adaptabilidade para esses novos tempos, em que a velocidade da obsolescência cresce, exige constantes ajustamentos diante de um mercado mais volátil e mais competitivo. Logo, a velocidade de produção está intimamente relacionada com a velocidade da circulação dos produtos. Não há dúvidas que tal rotatividade produtiva gera, para a economia como um todo, resultados bastante positivos. Isso é concreto tão somente porque nas sociedades com um grande estoque de bens de consumo duráveis, como ressaltam Sweezy e Baran (1978), um elemento importante da procura total por bens e serviços se estabelece na necessidade de troca de parte desse estoque quando se desgasta, ou quando é posta de lado. Ou seja, como ponderam os autores, a obsolescência pré-fabricada "aumenta a taxa de desgaste e frequentes modificações no modelo aumentam a taxa de substituição".

Outra forma de auxiliar o controle dos produtos está embasada nos três conceitos que Packard (1965) definiu da obsolescência, a saber: 1. Obsolescência de função. Nesta situação, um produto existente torna-se antiquado quando é introduzido um produto que executa melhor a função; 2. Obsolescência de qualidade. Neste caso, quando planejado, um produto quebra-se ou se gasta em determinado tempo, geralmente não muito longo e 3. Obsolescência de desejabilidade. Nesta situação, um produto que ainda está sólido, em termos de qualidade ou performance, torna-se "gasto" em nossa mente porque um aprimoramento de estilo ou outra modificação faz com que fique menos desejável. (PACKARD apud ANDRADE, 2007, p.76, grifos do autor)

Andrade (2007) postula que a obsolescência induzida da mercadoria pode ser observada, de forma clara, com maior intensidade nesses últimos quarenta anos, agindo no cotidiano social através do decréscimo da vida útil de cada objeto de consumo, graças ao grande desenvolvimento da tecnologia.

Em paralelo, o custo dos produtos obsoletos e suas consequências é outro fator destacado por Peinado e Graeml (2007, p. 386-387), que enfatizam que os produtos lançados, independente do grau de relevância da sua alteração, resultam no processo de "desova" dos produtos defasados. Afinal, quem gosta de comprar produtos velhos? O ciclo é fechado com a liquidação dos produtos antigos, com o consumo por oportunidade de um produto no estágio de declínio e pela ativação de uma nova cadeia produtiva, para o lançamento e o 
consumo do que aparentemente há de mais novo no mercado - atribuindo, por conseguinte, à publicidade um papel capital no processo.

Tal cenário, como ressaltado por Ferrari (2008, p.39), se estrutura na contemplação das maravilhas que a produção e a técnica proporcionam. Por outro lado, o autor também traz ênfase sobre o esquecimento, a alienação do homem em relação a si mesmo e aos outros e sobre o processo de produção daquilo que aparece. Assim, a mercadoria, produto do trabalho humano, transcende e escapa ao controle do produtor (GORENDER apud CARRASCOZA et al, 2007, p.69). Cenário mais do que "apropriado" para o crescimento do consumo, nos fazendo enxergar que, se o tempo de vida dos produtos é planejado, o nosso consumo também é.

Essas circunstâncias evidenciam a complexidade do mosaico no qual são inseridos a produção em massa, o planejamento da obsolescência e o consumo. Bauman (2008, p.31) pontua que nos mercados de consumidores-mercadorias existe a necessidade de se substituir, constantemente, objetos de consumo "defasados" para o crescimento constante das vendas, com base na vã e ilusória tentativa de satisfação de desejos. Sendo assim, instigada pelos conceitos de velocidade, transformação e obsolescência, a orientação do mercado se projeta muito mais na esfera do consumo do que no da produção (ENNE, 2006, p.22).

É importante observar ainda que, nessa conjuntura estratégica, ao contrário do pensamento ecológico, a existência é marcada pelo signo da abundancia material percebida como natural - inexistindo a ideia de estocar ou poupar para o futuro, pois tudo o que se deseja estaria, de alguma forma, disponível "aqui e agora" no mundo, para ser tomado. (ROCHA; BARROS, 2008, p.197).

Não é a toa, portanto, que a sociedade de consumidores desvaloriza a durabilidade, igualando "velho" a "defasado", impróprio para continuar sendo utilizado e destinado à lata de lixo (BAUMAN, 2008, p.31). Este é um ponto interessante, que vale a pena ser considerado, pois se a falta de consciência para o futuro é real, a falta de consciência para o consumo segue os mesmos princípios. Segundo Rocha e Barros (2008, p.190) o consumo moderno, muitas vezes, expressa o que o senso comum chama de irracionalidade econômica ou, em outras palavras, a prevalência da dimensão simbólica sobre a perspectiva instrumental ou utilitária. Complementando: 
O "querer" rege a busca pelas mercadorias, e os quereres são transitórios em um sistema econômico em que a lógica produtiva, revestida pelas estratégias de marketing, sustenta aquilo que definimos como obsolescência simbólica programada, ou seja: os produtos, a partir de ciclos regidos por movimentos de moda, de mudanças de gostos, de inovações e renovações tecnológicas e estéticas, são periodicamente lançados ao descarte motivado, à troca por novos modelos, por gadgets que se tornam manias sazonais. Produtos outrora inexistentes, que representam inovações tecnológicas, como o telefone celular, transitam do apelo de venda por ser novidade, para depois se tornar progressivamente um commoditie, que vai ganhando espaço [...] corresponde a um mercado que sustenta a ditadura do novo, a necessidade de obter o modelo mais recente, o lançamento que nem todos possuirão de imediato, de forma cada vez mais acelerada (CASAQUI, 2008, p.31).

Não é difícil, consequentemente, concluirmos que a concorrência mais "nociva" presente na economia capitalista, é a concorrência que os produtos novos travam com os antigos. Exatamente o que Schumpeter (1982) denominou de processo de destruição criativa5. Complementada pelo que defende Frederico (2008, p.81) ao afirmar que a realidade foi abolida e substituída por uma nova realidade, fornecida pelos meios de comunicação de massa e pela publicidade. A nosso ver, totalmente alicerçada pelo estímulo ampliado para o consumo.

Obviamente entendemos que a mudança é iniciada no produtor, como bem lembra Leite (2000, p.52). Tal produtor empreende esforços para "educar" seus consumidores a desejarem novas coisas, ou coisas diferentes, de alguma forma, daquelas que têm o hábito de consumir. Daí a prescrição da destruição criadora: a substituição de artigos, produtos e hábitos de consumir por outros, totalmente novos.

O interesse pelo acompanhamento do ciclo de vida dos produtos, consequentemente aflora na tentativa de prolongá-lo ou substituí-lo, dependendo dos consumidores e dos lucros do negócio. Toda essa preocupação é mediada por cálculos estatísticos que apontam os caminhos a serem seguidos. De acor-

5 A destruição criativa, basicamente é a sucessão do novo em relação ao velho, a substituição. Por exemplo, a chegada do Ipod, resultou na parada de fabricação do walkman e na decadência do discman. 
do com amostras significativas, é possível entender, por exemplo, o comportamento dos produtos e assim traçar seu "perfil", podendo-se calcular quais são produtos que atendem às aspirações presentes numa troca e quais não atendem - não esquecendo que, em seguida, tudo deve ser traduzido via argumentos publicitários.

Por essas e por outras, a publicidade se constitui como a chave para levar a crer que os novos produtos são quase sempre imprescindíveis na vida dos consumidores, afinal apenas a partir da sua aquisição se "pode saciar as necessidades que são criadas através da própria propaganda” (ANDRADE, 2007, p.40). O autor ainda acrescenta: "foi dessa forma que a obsolescência da desejabilidade se afirmou intensamente na cabeça de todos".

Quando refletimos sobre produção, consumo e publicidade, mesmo que à primeira vista as performances de cada esfera pareçam delimitadas a espaços previamente definidos e extremamente entrelaçados, a complexidade dessa ligação amplia, sobremodo, a atuação de cada um dos três campos elencados. A economia, a cultura e as relações que se firmam entre os atores inseridos no sistema produtivo e de consumo nos campos em questão, principalmente a partir do ponto de vista do capitalismo tardio, são, portanto, instâncias mais amplas e que evidenciam experiências e dimensões de consumo de acordo com diferentes perspectivas e/ou mediações, incidindo fortemente sobre a forma como se percebe e se vive o consumo na contemporaneidade.

\section{CONSIDERAÇÕES FINAIS}

Talvez seja senso comum afirmar que o consumo resultou do desejo que, por sua vez, revolucionou as técnicas e as formas de produção que, para se manterem vivas, alteraram quase irreversivelmente o comportamento, as necessidades, os desejos e os hábitos de cada indivíduo e da sociedade. Contudo, o fato que não podemos negar é que a produção em larga escala, o planejamento da obsolescência e a "era do excesso" contribuíram, enormemente, para a instauração da cultura de uma sociedade do descartável - na qual as mercadorias prescindem de uma velocidade de substituição bastante acelerada.

Por outro lado, se a obsolescência planejada diminui o ciclo de vida dos produtos, ao mesmo tempo em que visa à agilidade e a repetição sistemática do consumo das novidades, também atua diretamente sobre a constituição 
das identidades alicerçadas nos "modos de consumir" - tudo isso, a nosso ver, engendra e solicita a ampla atuação do marketing e da comunicação nesse complexo cenário de mercado. Assim sendo, a publicidade se estabelece como o instrumento que alicerça o terreno - ajudando a sedimentar as identidades relacionadas ao consumo - e constrói os pilares para os movimentos ideológicos. Isso ocorre porque, como ressaltamos anteriormente, a dificuldade contemporânea não mais reside na produção, como na época do fordismo, mas na circulação e nas vendas das mercadorias produzidas - o que atribui à divulgação publicitária um papel fundamental.

Soma-se a isso o fato de que, na outra ponta, temos a produção em massa exigindo estratégias eficazes para um consumo também massivo - e é justamente nesse lócus que a publicidade vai encontrar, a partir da demanda, a essência da sua existência: a produção argumentativa-discursiva das necessidades dos consumidores em potencial.

Isso faz com que o seu papel transcenda o caráter meramente informativo - já que, em si, ela é um produto de ordem sociocultural - e, como postulam Costa e Mendes (2012), sua íntima relação e imbricamento com a sociedade faz da publicidade "um reflexo da cultura contemporânea, podendo ser fator dinâmico de evolução por meio de sua estratégia sugestiva”.

Por conseguinte não fica difícil perceber que, ao acompanhar e dialogar com o desenvolvimento de uma sociedade de consumidores, a publicidade para responder as demandas produtivas - necessita dialogar com seus públicos "nas construções retóricas voltadas menos para a qualidade dos produtos e mais para a emoção que provocam" (CARRASCOZA, 2008, p.222). A nosso ver, tais "emoções" são traduzidas no estímulo ao desejo por objetos de durabilidade efêmera, produzidos para o rápido descarte e constante substituição.

Dessa forma, o estímulo ao consumo, a construção de identidades atreladas à posse de mercadorias e o planejamento da obsolescência também fazem parte do "pacote". Não por acaso, o mercado e sua economia lucrativa abraçaram a celeridade como base para a vida útil dos produtos e a publicidade se encarregou de dar vazão à alta produção, na medida em que estimula os potenciais consumidores com sua retórica acerca das necessidades.

Por fim, não é difícil concluir que, por seu potencial persuasivo e gerador de vendas, a publicidade é o elo entre a produção e o consumo intermediando 
assim, na "era do excesso", o escoamento da abundância dos bens e os desejos de autorealização através do ato de consumir, ao mesmo tempo em que estimula o despontar de novos padrões de consumo e dimensões identitárias que transcendem as meras necessidades físicas e/ou psicológicas.

\section{REFERÊNCIAS}

ANDRADE, Vanessa Batista de. Estética da mercadoria e obsolescência: um estudo da indução ao consumo no capitalismo atual. 2007. 119f. Dissertação de Mestrado em Sociologia Pós-Graduação em Sociologia, Faculdade de Ciências e Letras Unesp/Araraquara, 2007.

BAUMAN, Z. Vida para consumo: a transformação de pessoas em mercadoria. Rio de Janeiro: Jorge Zahar Ed., 2008.

BAUDRILLARD, Jean. A Sociedade de Consumo. Tradução de Artur Mourão. Rio de Janeiro: Elfos Editora, 1995.

BOURDIEU, Pierre. Distinction. Cambridge, Mass.: Harvard University, 1984.

CARRASCOZA, João et al. A publicidade da Coca-Cola "Happiness Factory" e o imaginário do sistema produtivo na sociedade de consumo. IN: Comunicação, Mídia e Consumo. v. 4 n.11. São Paulo: ESPM, 2007.

CARRASCOZA, João. Publicidade: o sonho do consumo e a realidade de produção. IN: BACCEGA, Maria aparecida (org.). Comunicação e Culturas do Consumo. São Paulo: Ed. Atlas, 2008.

CARREIRA, José Carlos. Da estratégia do anunciante à comunicação publicitária: o caminho do significado. In: PEREZ, Clotilde; BARBOSA, Ivan (Org.). Hiperpublicidade: Fundamentos e Interfaces. v. 1. São Paulo: Thomson Learning, 2007. p. 91-123

CASAQUI, Vander. Do mundo do trabalho a retórica do consumo: um estudo das representações do trabalho na publicidade contemporânea. IN: BACCEGA, Maria aparecida (org.). Comunicação e Culturas do Consumo. São Paulo: Ed. Atlas, 2008.

COSTA, Maria Ivanúcia, MENDES. Marcília. A publicidade como ferramenta de consumo: uma reflexão sobre a produção de necessidades, 2012. Disponível em: http://www.bocc.ubi. pt/_listas/tematica.php?codtema=10. Acesso em 20 Mai. 2013.

DAVIS, Mark M. et al. Fundamentos da administração da produção. 3. ed. Tradução de Eduardo D’Agord Schaan et al. Porto Alegre: Bookman Editora, 2001.

DI NALLO, Egeria. Meeting points: soluções de Marketing para uma Sociedade Complexa. São Paulo: Cobra Editora e Marketing, 1999.

ENNE, Ana Lucia. À perplexidade, a complexidade: caminhos para pensar a relação entre consumo e identidade nas sociedades contemporâneas. IN: Comunicação, Mídia e Consumo. v. 3 n.7. São Paulo: ESPM, 2006. 
FEATHERSTONE, Mike. Cultura de consumo e pós-modernismo. São Paulo, Studio Nobel, 1995.

FERRARI, Sônia Campaner M. A fantasmagoria do consumo e sua transfiguração. IN: BACCEGA, Maria aparecida (org.). Comunicação e Culturas do Consumo. São Paulo: Ed. Atlas, 2008. p. 35-52.

FILHO, Clóvis de Barros, LOPEZ, Felipe. A dominação pelo gosto: o consumo na sociologia de Bourdieu. IN: BACCEGA, Maria aparecida (org.). Comunicação e Culturas do Consumo. São Paulo: Ed. Atlas, 2008. p. 186-202.

FREDERICO, Celso. O consumo nas visões de Marx. IN: BACCEGA, Maria aparecida (org.). Comunicação e Culturas do Consumo. São Paulo: Ed. Atlas, 2008. p. 79-87.

KREUTZ, Elizete, FERNÁNDEZ, Francisco. Google: A narrativa de uma marca mutante. IN: Comunicação, Mídia e Consumo. v. 6 n.16. São Paulo: ESPM, 2009.

LEITE, Emanuel. O fenômeno do empreendedorismo: criando riquezas. Recife: Bagaço, 2000.

LIPOVETSKY, Gilles. A felicidade paradoxal: ensaio sobre uma sociedade de hiperconsumo. São Paulo: Companhia das Letras, 2007.

LUKÁCS, John. O enigma do consumismo moderno. IN: CAMPBELL, Colin. A ética romântica e o espírito do consumismo moderno. Tradução de Mauro Gama. Rio de Janeiro: Rocco, 2001. p. 57-86.

MAAR, Wolfgang. Habermas, esfera pública e publicidade. IN: BACCEGA, Maria aparecida (org.). Comunicação e Culturas do Consumo. São Paulo: Ed. Atlas, 2008. p. 216-229.

PEINADO, Jurandir, GRAEML, Alexandre Reis. Administração da Produção: operações industriais e de serviços. Curitiba: Unicenp, 2007.

MARGOLIS, Iara. As características da embalagem e o processo de tomada de decisão do consumidor no ato da compra. 2012. 39of. Dissertação de Mestrado em Engenharia de Produção Mecânica - Pós-Graduação em Engenharia Mecânica, Universidade Federal de Pernambuco, Pernambuco, 2012.

ROCHA, Everardo, BARROS, Carla. Entre mundos distintos: notas sobre comunicação e consumo em um grupo social. IN: BACCEGA, Maria aparecida (org.). Comunicação e Culturas do Consumo. São Paulo: Ed. Atlas, 2008.

SLACK, Nigel et al. Administração da Produção. Tradução Henrique Luiz Corrêa. 3 ed. São Paulo: Atlas, 2009.

SCHUMPETER, Joseph A Teoria do Desenvolvimento Econômico: Uma investigação sobre Lucros, Capital, Crédito, Juro e o Ciclo Econômico. Tradução de Maria Sílvia Possas. Ed. Abril S.A. Cultural e Industrial, São Paulo, 1982.

SWEEZY, Paul M.; BARAN, Paul A. Capitalismo monopolista: ensaio sobre a ordem econômica e social americana. Rio de Janeiro: Zahar Editores, 1978. 
WOODWARD, Kathryn. Identidade e Diferença: uma introdução teórica e conceitual. In: SILVA, Tomaz Tadeu (org.); HALL, Stuart; WOODWARD, Kathryn. Identidade e Diferença: a perspectiva dos estudos culturais. 11a ed.- Petrópolis, RJ: Vozes, 2012, p. 7-72.

RECEBIDO EM: 22/05/2013

ACEITO PARA PUBLICAÇÃO: 01/07/2013

\section{Karla Patriota Bronsztein}

Doutora em Sociologia e mestre em Comunicação pela Universidade Federal de Pernambuco - UFPE, professora do Programa de Pós-graduação em Comunicação. Autora e organizadora dos livros Publicidade llimitada: reflexos e reflexões sobre comunicação e consumo e A natureza das Mídias Digitais. Novos paradigmas para a Publicidade. É líder do Grupo de Pesquisa do CNPq Publicidade nas novas mídias e narrativas de consumo.

\section{Iara Margolis}

Mestre em Engenharia Mecânica pela Universidade Federal de Pernambuco - UFPE. Professora da Graduação em Engenharia de Produção e Administração da Faculdade Boa Viagem-FBV/ DeVry. 
